九州大学学術情報リポジトリ

Kyushu University Institutional Repository

Performance of NACA Cambered and Symmetrical Airfoils as Rear Spoilers on Race Car Aerodynamic Drag \& Lift: Computational Fluid Dynamics Study

Dey, Shamudra

Department of Mechanical Engineering, Shahjalal University of Science and Technology

Saha, Ranabir

Department of Mechanical Engineering, Bangladesh University of Engineering and Technology

https://doi.org/10.5109/4102505

出版情報: Proceedings of International Exchange and Innovation Conference on Engineering \& Sciences (IEICES). 6, pp. 292-298, 2020-10-22. Interdisciplinary Graduate School of Engineering Sciences, Kyushu University バージョン:

権利関係 : 


\title{
Performance of NACA Cambered and Symmetrical Airfoils as Rear Spoilers on Race Car Aerodynamic Drag \& Lift: Computational Fluid Dynamics Study
}

\author{
Shamudra Dey ${ }^{1}$, Ranabir Saha ${ }^{2}$ \\ ${ }^{1}$ Department of Mechanical Engineering, Shahjalal University of Science and Technology, Sylhet-3114, Bangladesh, \\ ${ }^{2}$ Department of Mechanical Engineering, Bangladesh University of Engineering and Technology, Dhaka-1100, \\ Bangladesh. \\ Corresponding author email: shamudra-mee@student.sust.edu
}

\begin{abstract}
In the current study, the aerodynamic effects of NACA 2412 cambered \& NACA 0012 symmetric airfoils as rear spoilers on a race car were analyzed using the Computational Fluid Dynamics (CFD) technique. Overall nine simulations have been conducted: one with the flow around the simplistic high-speed sports car model with no spoiler and eight for the representation of the flow across the sports car model with spoilers constructed of NACA 2412 and $N A C A 0012$ airfoil having $-6^{\circ},-3^{\circ},+3^{\circ}$ and $+6^{\circ}$ angles of attack, accordingly. The study was conducted using the $k$ epsilon method as well as for a velocity of $40 \mathrm{~m} / \mathrm{s}$. Grid independence study had been conducted and the CFD analysis had been checked by contrasting the results with the famous vehicle aerodynamics experimental study of Ahmed. Among the spoilers studied, this was found that the NACA 0012 with a $+6^{\circ}$ angle of attack ensures a drag reduction of $2.16 \%$ and a significant lift reduction of $111.22 \%$. The results of the rear spoiler were described from an aerodynamics viewpoint.
\end{abstract}

Keywords: Aerodynamics, Race car, Spoiler, Drag, Lift

\section{INTRODUCTION}

Comprehension of aerodynamic performance is very vital to ensure good experience of driving and safety [14]. In this current era, automotive aerodynamics plays a key role in design concepts related to safety, economical and environmental considerations. It is calculated that aerodynamic drag is really the predominant source of resistance as vehicles exceed speeds of $80 \mathrm{~km} / \mathrm{h}$ or even more, particularly provided that $65 \%$ of the power needed at $110 \mathrm{~km} / \mathrm{h}$ is absorbed as a result of aerodynamic drag control. Aerodynamics of sports cars is mainly influenced by their design and airflow over body ducts and surfaces $[5,6]$. The use of spoilers in the automobile sector has increased. Typically, the back spoiler is mounted on the rear hatch of a compact car. The integrated spoiler can disperse the airflow through a car, that lessens the turbulence at the rear of the automobile by adding more pressure to the rear deck and ensures better traction, faster turning, acceleration and brake as well as increasing the vehicle safety [7]. While the rear spoilers have become a key player in the modern automotive industry, very few research have been done previously to compare the NACA cambered and noncambered airfoils as rear spoilers on the race car. Since airfoils are aerodynamically effective geometric structures, this computational study will give us a direct insight into the contrasting performance in selected NACA 2412 camber and NACA 0012 symmetric airfoils as rear spoilers on the race car.

As an integral part of the current automobile sector, there seem to be a limited number of related literature studies that combine both mathematical studies and exploratory rear spoiler validation. Since drag has a direct correlation to fuel usage, almost all of the researchers have emphasized on drag reduction instead of car safety, proper driving performance and convenience. In the framework of designing race cars, the aerodynamics of light-weight automobiles should be strongly considered in terms of reducing drag forces and enhance high-speed safety down forces [8-10]. Tsai et al. have assessed the effect of five different rear spoilers on aerodynamic characteristics and aeroacoustics of the Honda S2000 under $180 \mathrm{~km} / \mathrm{h}$. Using the CFD method, the sound pressure rates for every case were estimated and drag coefficients ranging from 0.4 to 0.51 and lift coefficients ranging from 0.001 to 0.06 were also calculated. In the particular instance without the spoiler, the minimum drag coefficient is calculated and reduces in the different spoiler configurations in terms of reducing the lift coefficient [8]. The computational study of drag reduction is carried out by Barbut et al. [11], Rouméas et al. [12] on the passenger car and Guilmineau [13] on the Ahmed Body. Islam and Mamun [14] conducted both analytical and experimental research to compute aerodynamic drag, although their research was focused solely on passenger vehicles. Kim has examined the effect of the rear spoilers on the characteristics of wake flow and drag for large public buses. The author determined that the drag coefficient for the bus was 0.518 , and is within $4 \%$ of the actual data identified by the $1 / 16$ size design commercial bus in the reference tunnel [15]. Jahanmiri investigated with drag reduction on Ahmed's body by using application of effective flow control methods [16]. The primary goal of this particular study is to determine the desired angle of attack for NACA 0012 and NACA 2412 rear spoiler in order to minimize both drag and lift on the race car.

\section{PROBLEM FORMULATION AND SOLID GEOMETRY MODELS}

The force applied on the automobile in a reverse direction to its traveling path is termed drag. On contrary, the force $90^{\circ}$ to the drag as well as normal to the field is termed lift. The greater the drag force, the higher horsepower and fuel usage are actually needed. Drag and lift forces can be presented in a dimensionless form-the drag and lift coefficients $\left(\mathrm{C}_{\mathrm{D}}\right.$ and $\left.\mathrm{C}_{\mathrm{L}}\right)$ are defined as: 


$$
\begin{aligned}
C_{D} & =\frac{\text { Drag force }}{\left(\rho V^{2} A\right) / 2} \\
C_{L} & =\frac{\text { Lift force }}{\left(\rho V^{2} A\right) / 2}
\end{aligned}
$$

An image has been provided to show the forces acting on a running car (Fig.1).

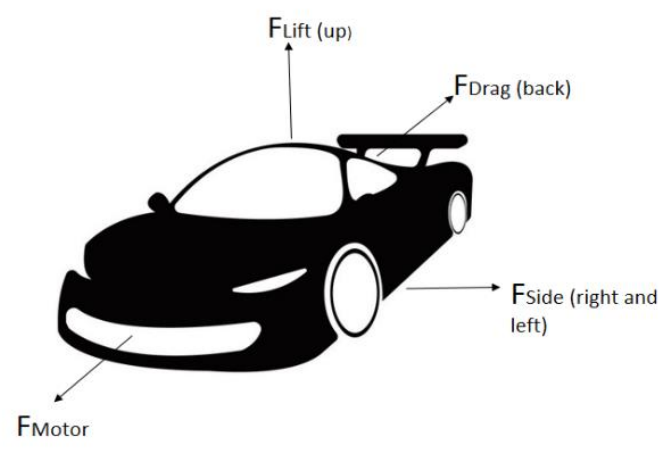

Fig. 1. Forces acting on a running sports car
A total of ten sports (three types) car models were developed with SOLIDWORKS 2017 (Fig.2). Amongst which, eight NACA 2412 as well as NACA 0012 airfoil models developed spoilers with an attack angle of $-6,-3$, $+3,+6$ degrees, respectively. Both those airfoils are of similar thickness, but camber is the main difference between them. The two other solid geometry designs are the simplistic automotive model and the Ahmed model. For this study, the Ahmed body was used to validate the computational domain by contrasting the simulation result with the prominent experiment carried out by Ahmed [18]. The combined span of the prototype race car and the Ahmed body were $0.63105 \mathrm{~m}$. and $1.044 \mathrm{~m}$. respectively.

The combined span of the prototype race car and the Ahmed body were $0.63105 \mathrm{~m}$. and $1.044 \mathrm{~m}$. respectively. Solid models have been moved to the ANSYS Design Modeler, in which a model wind tunnel is being designed around the race car. This simulated wind tunnel is the mathematical domain of this research. An illustration (Fig.3) of the mathematical domain (race car with rear spoiler) was given below:

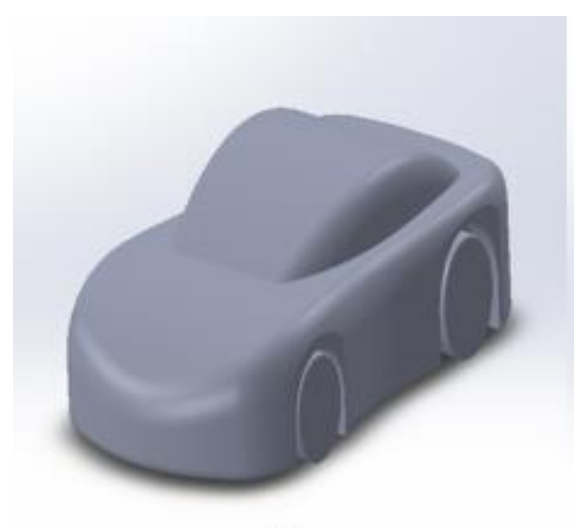

(a)

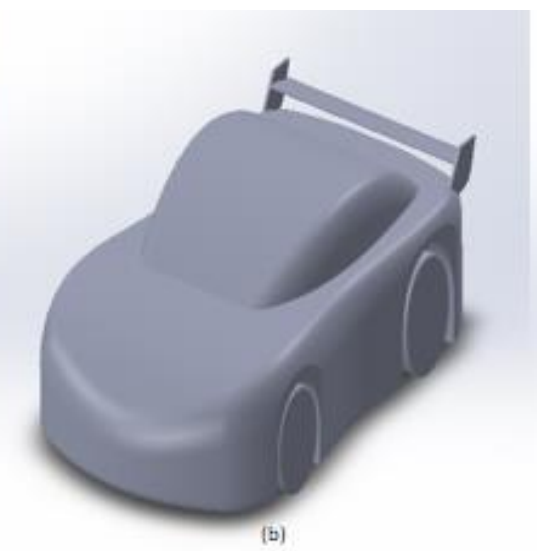

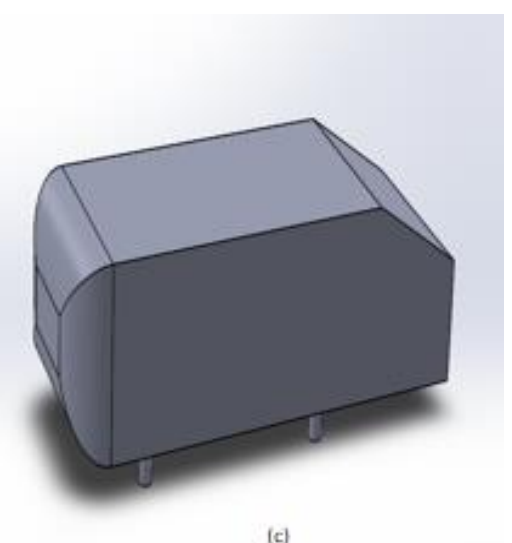

(c)

Fig. 2. (a) Solid geometry model of the simplistic race car (b) Solid geometry model of the sports car with NACA 0012 spoiler (c) Solid geometry model of Ahmed body with $25^{\circ}$ slant angle

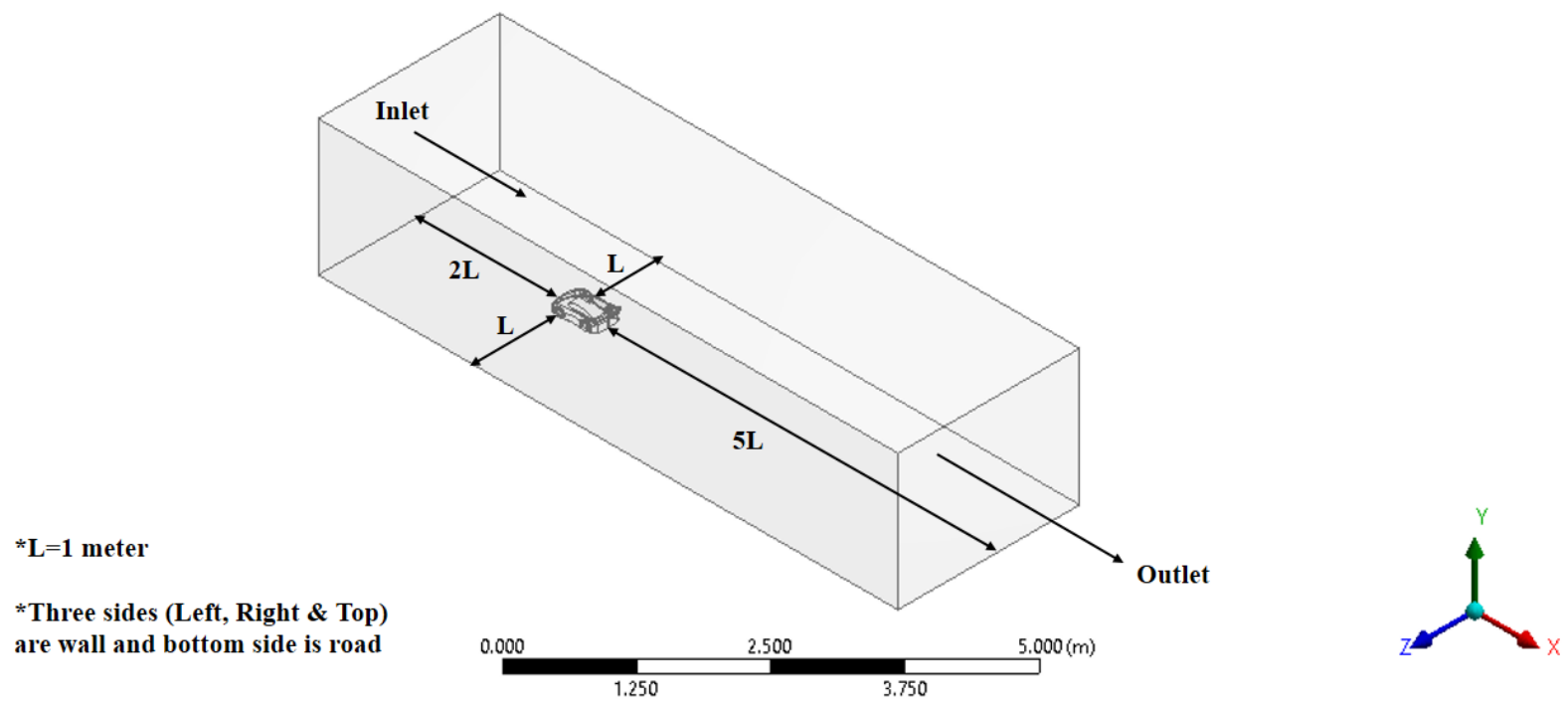

Fig. 3. Computational domain of the current work

\section{NUMERICAL METHODOLOGY}

CFD modelling has a wide variety of applications in different engineering fields such as aerodynamics, biofluid dynamics, renewable energy, heat exchanger units etc. [19]. Favre-averaged N-S formulas are used in which the time-averaged impacts of flow turbulence are taken into account. The numerical model uses transport formulas in case of turbulent kinetic energy as well as its rate of dissipation, the realizable $\mathrm{k}-\varepsilon$ model. The Newtonian fluid equation can be written: 


$$
\begin{aligned}
& \frac{\partial\left(\rho u_{i}\right)}{\partial x_{i}}=0 \\
& \begin{aligned}
\frac{\partial\left(\rho u_{i} u_{j}\right)}{\partial x_{j}}+\frac{\partial P}{\partial x_{i}}= & \frac{\partial}{\partial x_{i}}\left(\mu \left(\frac{\partial u_{i}}{\partial x_{j}}+\frac{\partial u_{j}}{\partial x_{i}}\right.\right. \\
& \left.-\frac{2}{3} \delta_{i j} \frac{\partial u_{k}}{\partial x_{k}}\right) \\
& +\mu_{t}\left(\frac{\partial u_{i}}{\partial x_{j}}+\frac{\partial u_{j}}{\partial x_{i}}-\frac{2}{3} \delta_{i j} \frac{\partial u_{k}}{\partial x_{k}}\right) \\
& \left.-\frac{2}{3} \rho k \delta_{i j}\right)-\rho g_{i} \\
\frac{\partial\left(\rho u_{i} H\right)}{\partial x_{i}}=\frac{\partial}{\partial x_{i}}[ & \mu_{j}\left(\mu \left(\frac{\partial u_{i}}{\partial x_{j}}+\frac{\partial u_{j}}{\partial x_{i}}\right.\right. \\
& \left.-\frac{2}{3} \delta_{i j} \frac{\partial u_{k}}{\partial x_{k}}\right) \\
& +\mu_{t}\left(\frac{\partial u_{i}}{\partial x_{j}}+\frac{\partial u_{j}}{\partial x_{i}}-\frac{2}{3} \delta_{i j} \frac{\partial u_{k}}{\partial x_{k}}\right) \\
& \left.\left.-\frac{2}{3} \rho k \delta_{i j}\right)\right]-\rho g_{i} u_{i} \\
& -\mu_{t}\left(\frac{\partial u_{i}}{\partial x_{j}}+\frac{\partial u_{j}}{\partial x_{i}}-\frac{2}{3} \delta_{i j} \frac{\partial u_{k}}{\partial x_{k}}\right) \\
& -\frac{2}{3} \rho k \delta_{i j} \frac{\partial u_{i}}{\partial x_{i}}+\rho \varepsilon
\end{aligned}
\end{aligned}
$$

In which, $H=h+\frac{u^{2}}{2}$

In above equations, $\delta_{i j}$ is called Kronecker delta, $\mathrm{h}$ is thermal enthalpy, $\mu$ is the dynamic viscosity coefficient, $\mu_{t}$ is known as the turbulent eddy viscosity index and $k$ is considered as turbulent kinetic energy. Here, $k$ and $\mu_{t}$ are zero for streamline flow [14]. Two model transport equations are used to explain turbulent kinetic energy and steady state dissipation:

$$
\begin{aligned}
\frac{\partial}{\partial t}(\rho k)+\frac{\partial}{\partial x_{j}}\left(\rho k u_{j}\right) & \\
= & \frac{\partial}{\partial x_{j}}\left[\left(\mu+\frac{\mu_{t}}{\sigma_{k}}\right) \frac{\partial k}{\partial x_{j}}\right]+G_{k} \\
& +G_{b}-\rho \epsilon-Y_{M}+S_{K}
\end{aligned}
$$

$$
\begin{aligned}
\frac{\partial}{\partial t}(\rho \epsilon)+\frac{\partial}{\partial x_{j}}\left(\rho e u_{j}\right) & \\
= & \frac{\partial}{\partial x_{j}}\left[\left(\mu+\frac{\mu_{t}}{\sigma_{\epsilon}}\right) \frac{\partial k}{\partial x_{j}}\right] \\
& +\rho C_{1} S \epsilon-\rho C_{2} \frac{\epsilon^{2}}{k+\sqrt{v \epsilon}} \\
& +C_{1 \epsilon} \frac{\epsilon}{k} C_{3 \epsilon} G_{b} S_{\epsilon}
\end{aligned}
$$

The viscosity of the turbulence is measured using:

$$
\mu_{t}=\rho C_{\mu} \frac{k^{2}}{\epsilon}
$$

In which, the $C \mu$ is written:

$$
C_{\mu}=\frac{1}{A_{o}+A_{S} \frac{k U^{*}}{\epsilon}}
$$

The model constants are considered $C_{1 \mathscr{E}}=1.44, C_{2}=1.9$, $\sigma_{k}=1.0, \quad \sigma_{\mathscr{E}}=1.2$. The cell-centered finite-volume technique is used to collect conservative estimates of the governing equations for the regionally processed triangular mesh of lower skewness and higher orthogonal quality (Fig. 4). Integral conservation laws can be seen in the form of a cell volume and a surface integral equation:

$$
\frac{\partial}{\partial t} \int U d v+\oint F \cdot d s=\int Q d v
$$

It is replaced by the discrete form $\frac{\partial}{\partial t}(U v)+$ $\sum_{\text {cell faces }} F . s=Q v$ [17]. The number of grids that have been used in computation is around 2.16 million. Finer meshes were used throughout the race car for visualization purposes and performance analysis.

The complete numerical calculation is conducted on the ANSYS 15.0 Fluent. Air is specified as fluid and the aluminum is identified as solid and the necessary characteristics (density, viscosity, etc.) are established. In the context of model parameters, the appropriate inlet flow velocity condition of $40 \mathrm{~m} / \mathrm{s}$ shall be described as the inlet and the exit shall be kept as a pressure outlet of $0 \mathrm{~Pa}$. Such particular model parameters were studied in order to determine the aerodynamic performance of the race car at fast speed and to analyze data with a variety of literatures [18, 20]. Pressure speed coupling based coupled solution command is implemented in this study under custom relaxation considerations.

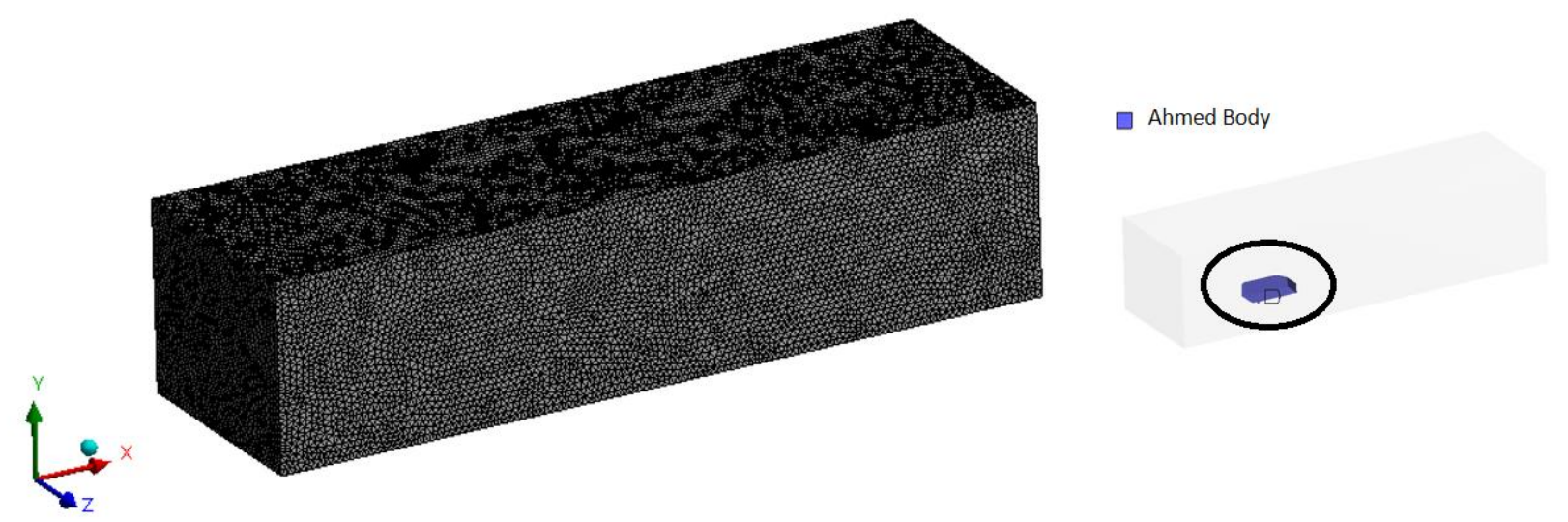

Fig. 4. Mesh generation over the Ahmed body (partially selected regions for better view) 


\section{RESULTS AND DISCUSSION}

In this section, the research was verified by a grid independence study and confirmed by contrasting the results with scientific results from existing literature. In addition, the effects of various aerodynamic performance have been discussed.

\subsection{Grid independence study}

A grid independence analysis was performed on the model of Ahmed's body. The main priority was given to the number of elements and the drag coefficient $\left(C_{D}\right)$. Therefore in grid sensitivity analysis, a total of three categories have been utilized for this objective: grid 1 , grid 2 and grid 3 with 0.94 million, 1.42 million and 2.16 million elements separately. Fig. 5 describes the result of grid sensitivity test and it can be understood that, for all three types of cases, drag coefficient values are almost similar. In this study, grid 3 has been used for all the CFD simulations.

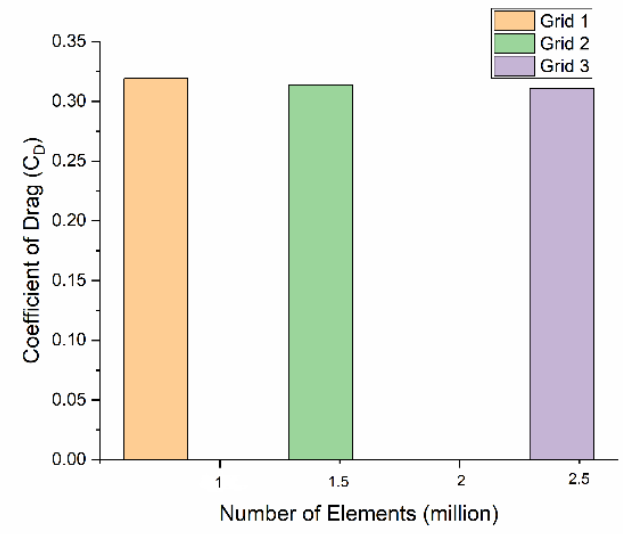

Fig 5. Grid independence study

\subsection{Validation}

The research was contrasted with a number of different academic publications. In order to confirm the computational domain of this CFD analysis, three supplementary simulations were performed on Ahmed body models with a velocity profile of $40 \mathrm{~m} / \mathrm{s}$ and $60 \mathrm{~m} / \mathrm{s}$. Table 1 displays the drag coefficient relation between the current CFD analysis and the Ahmed research [18, 20]. The maximum error is identified to be $8.74 \%$, which is reasonable.

Table 1. Contrast of CFD study \& experiment

\begin{tabular}{cccc}
\hline $\begin{array}{c}\text { Velocity } \\
{\left[\mathrm{ms}^{-1}\right]}\end{array}$ & $\begin{array}{c}\mathrm{C}_{\mathrm{D}} \text { of } \\
\text { Ahmed } \\
\text { Body } \\
(\mathrm{CFD})\end{array}$ & $\begin{array}{c}\mathrm{C}_{\mathrm{D}} \text { of Ahmed } \\
\text { Body } \\
\text { (Experiment) }\end{array}$ & Error (\%) \\
\hline $\begin{array}{c}40 \\
\left(25^{\circ} \text { slant }\right. \\
\text { angle }) \\
40\end{array}$ & 0.311 & 0.286 & $\mathbf{8 . 7 4}$ \\
$\begin{array}{c}35^{\circ} \text { slant } \\
\text { angle }) \\
60\end{array}$ & 0.297 & 0.279 & 6.45 \\
$\begin{array}{c}25^{\circ} \text { slant } \\
\text { angle })\end{array}$ & 0.307 & 0.298 & 3.02 \\
\hline \hline
\end{tabular}

4.3 Effect of Spoiler Angle of Attack on Drag Coefficient and Lift Coefficient
The drag coefficient value of the race car model without back spoiler is estimated to be 0.263 . When the spoilers are added to the back side of the race car, the drag coefficient amount has developed in all seven instances, excluding the race car model with NACA 0012 rear spoiler of $+6^{\circ}$ attack angle. The drag coefficient value was decreased by $2.16 \%$. The maximum drag increase of $17.11 \%$ is caused by NACA 2412 airfoil spoiler with $-3^{\circ}$ angle of attack. Fig. 6 shows the effect of spoiler angle of attack on drag coefficient.

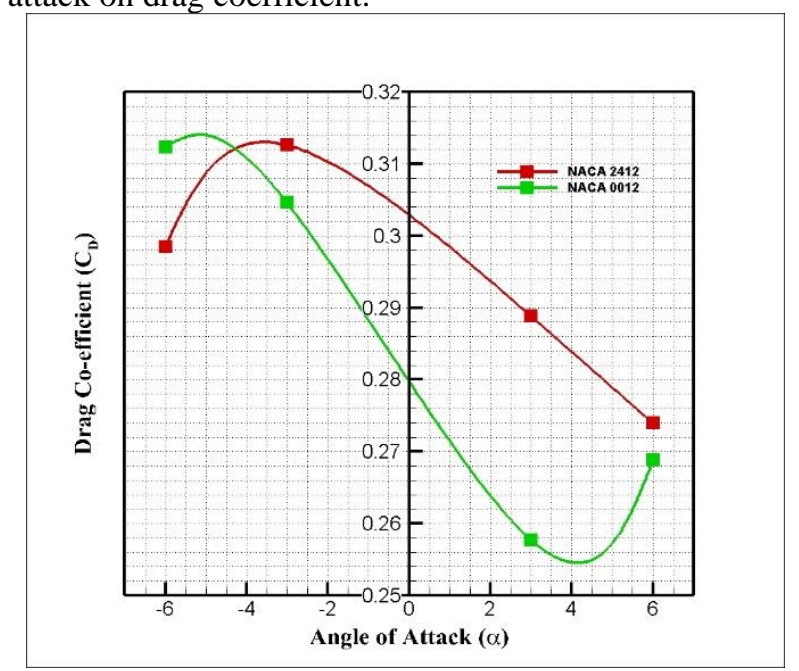

Fig 6. Effect of spoiler angle of attack on $C_{D}$.

The lift coefficient $\left(\mathrm{C}_{\mathrm{L}}\right)$ of the race car model without rear spoiler is estimated to be 0.311 . While the spoilers are mounted to the backside of the sports vehicle, the lift coefficient values have reduced in all eight situations. A peak lift reduction of $181 \%$ was accomplished with NACA 0012 rear spoiler with $-3^{\circ}$ angle of attack and a low lift reduction of $84 \%$ was accomplished with the NACA 2412 rear spoiler with $+6^{\circ}$ angle of attack. The role of the spoiler attack angle on the lift coefficient is shown in Figure 7.

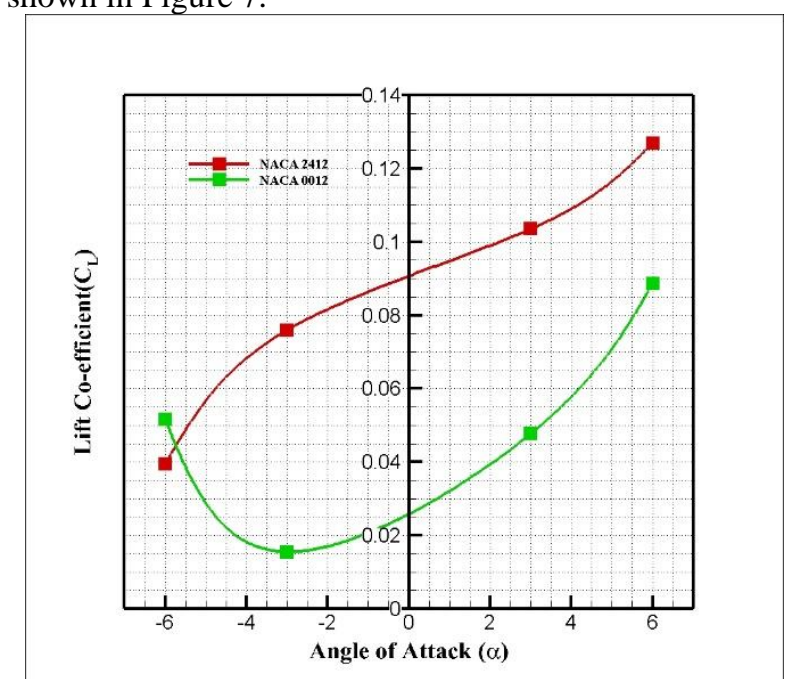

Fig. 7. Effect of spoiler angle of attack on $C_{L}$

4.4 Comparative Velocity \& Pressure Contours on the Symmetry plane of the Sports Car Body for Selected NACA Airfoil Spoilers

The velocity contours of the high-speed race car without and with spoilers (selected) on the ipsilateral plane are seen in Fig. 8 and the back spoiler car has wide and twin air swirl at the back side. The result demonstrates that the boundary-layer stream splits below the center of the back 
panel, and the flow speed is low from the point of separation. A slow-flow recirculation region, which existed due to the chaotic nature of the flow, can be observed on the back side of the race car without the rear spoiler. The air circulation recirculation is balanced after the rear spoiler is mounted. Smoother air flow with more balanced recirculation can be observed in the tail of the NACA 0012 spoiler sports car with $-3^{\circ}$ angle of attack. In the case of a racing car with no rear spoiler, the pressure is heavier toward the front of the car. A fairly low-speed area is created right across the border between the back window and the trunk. The pressure differential at the peak and the negative pressure at the bottom will minimize the lifting force on the rear of the vehicle. The distribution of pressure of the high-speed race car (with or without spoiler) is shown in image 9 . When the spoiler was mounted, a greater pressure region was found in that zone of the automotive.

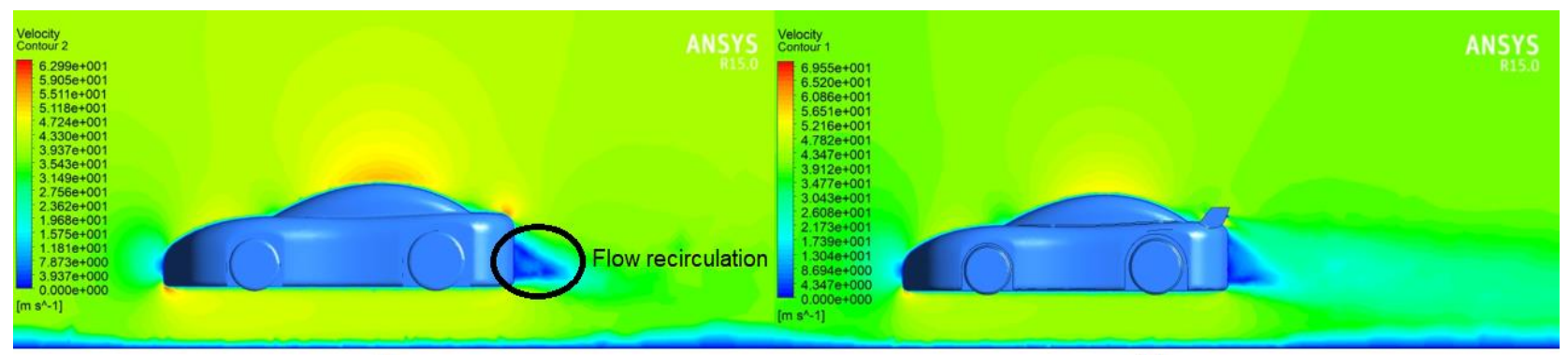

(a)

(b)

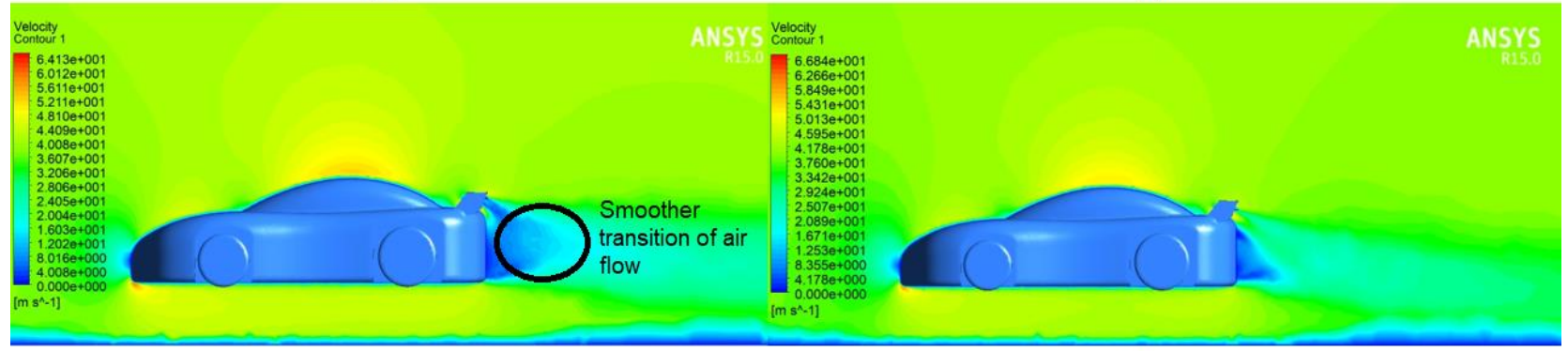

(c)

(d)

Fig. 8. Velocity contour on the symmetry plane for (a) sports car without rear spoiler (b) sports car with NACA 0012 spoiler of $+6^{\circ}$ AOA (c) sports car with NACA 0012 spoiler of $-3^{\circ}$ AOA (d) sports car with NACA 2412 spoiler of $+6^{\circ} \mathrm{AOA}$

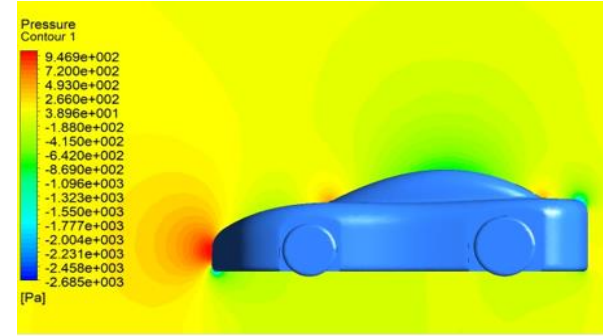

(a)

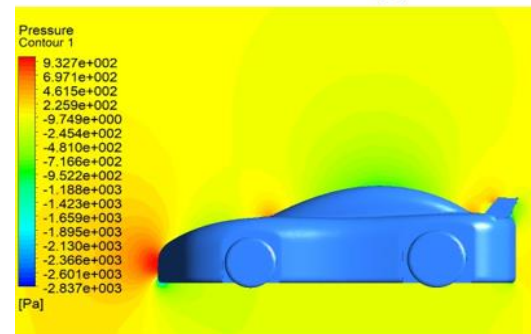

(c)

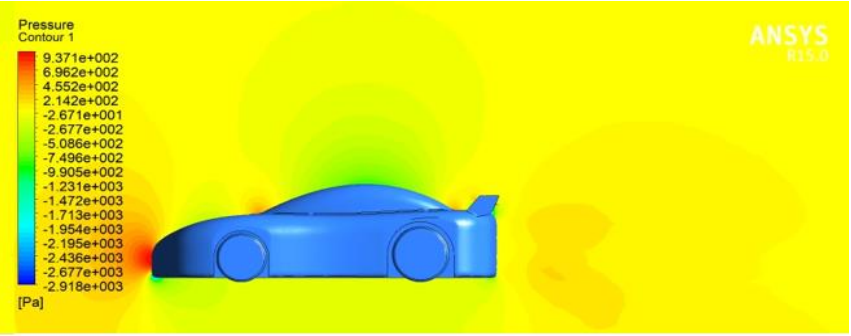

(b)

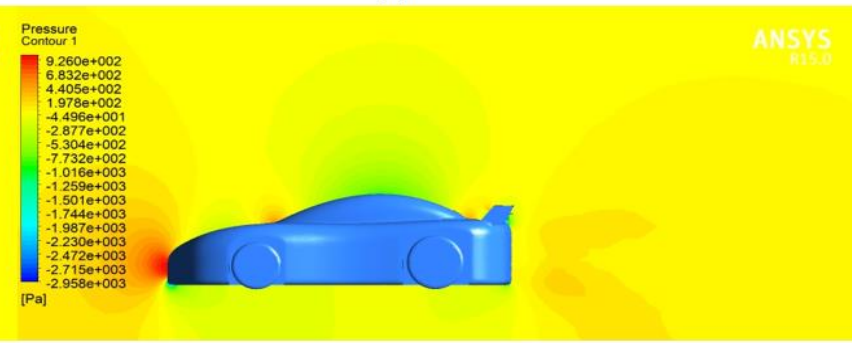

(d)

Fig. 9. Pressure contour on the symmetry plane for (a) sports car without rear spoiler (b) sports car with NACA 0012 spoiler of $+6^{\circ}$ AOA (c) sports car with NACA 0012 spoiler of $-3^{\circ}$ AOA (d) sports car with NACA 2412 spoiler of $+6^{\circ} \mathrm{AOA}$

\subsection{Turbulence Intensity on the Symmetry plane of the Sports Car Body for selected NACA Airfoil Spoilers}

Turbulence intensity is defined as the ratio of the standard deviation of the oscillating wind velocity to the mean wind velocity. Nevertheless, this represents the magnitude of the fluctuation of the speed of the wind. It is clear from Fig.10 that the rear spoilers are of great significance to the turbulence. As shown in the colors of the contour, it can be seen that there is less turbulence intensity behind the car in the case of a rear spoiler with a $+6^{\circ}$ angle of attack. 


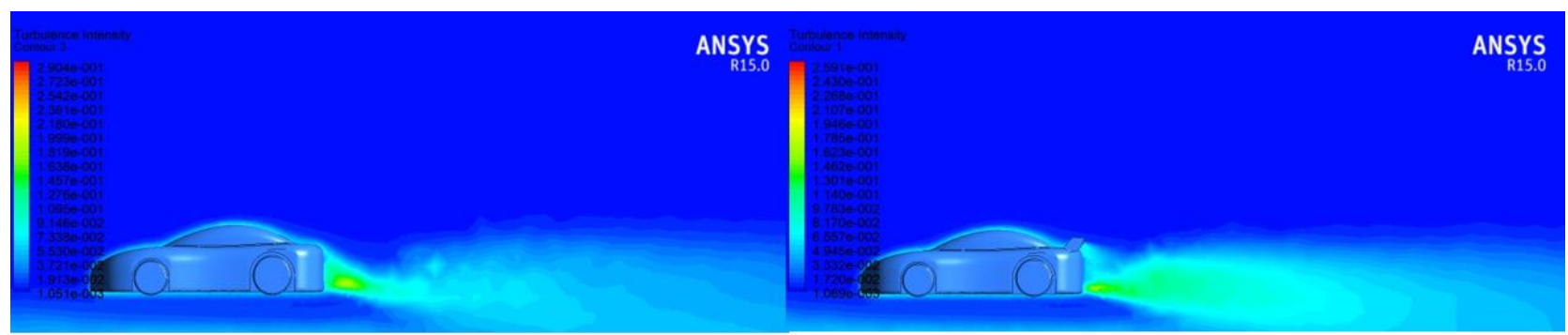

(a)

(b)

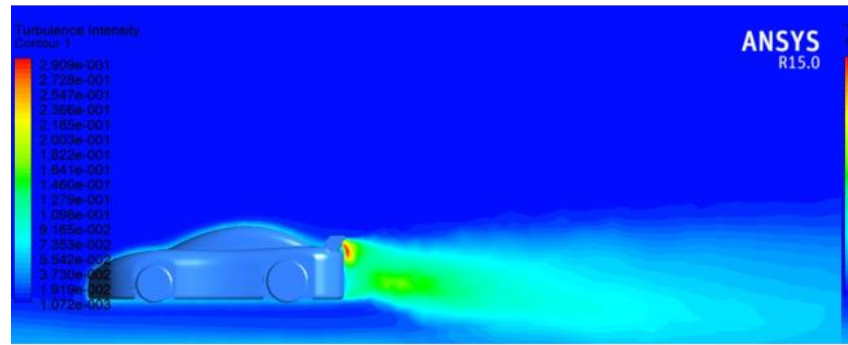

(c)

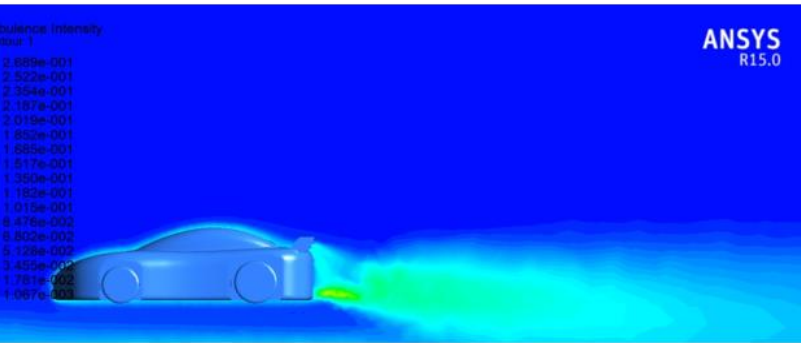

(d)

Fig 10. Turbulence intensity contour on the symmetry plane for (a) sports car without rear spoiler (b) sports car with NACA 0012 spoiler of $+6^{\circ}$ AOA (c) sports car with NACA 0012 spoiler of $-3^{\circ}$ AOA (d) sports car with NACA 2412 spoiler of $+6^{\circ} \mathrm{AOA}$

\subsection{Information of Percentage Drag and Lift Difference for NACA Airfoil Spoilers}

Table $2 \& 3$ outlines the percentage of drag \& lift adjustment when the cambered and symmetrical airfoils are mounted as back spoilers. Thus, the positive (+) sign implies increase \& negative (-) sign means decrease. Maximum lift decline was accomplished by the rear spoiler NACA 0012 with $-3^{\circ}$ angle of attack. Drag rose in all cases of NACA 2412 and 0012 airfoil spoilers apart from NACA 0012 with a $+6^{\circ}$ attack angle configuration.

Table 2. Overview of the percentage variation in $C_{D} \&$ $\mathrm{C}_{\mathrm{L}}$ values for NACA 2412 rear spoilers

\begin{tabular}{c|c|c}
\hline \hline \multirow{2}{*}{$\begin{array}{c}\text { Angle of } \\
\text { Attack }\left[{ }^{\circ}\right]\end{array}$} & \multicolumn{2}{|c}{ NACA 2412 Rear Spoiler } \\
\cline { 2 - 3 } & $\mathrm{C}_{\mathrm{D}}$ Difference & $\%_{\mathrm{C}}$ Difference \\
\hline-6 & $+12.53 \%$ & $-154.95 \%$ \\
-3 & $+17.11 \%$ & $-121.43 \%$ \\
+3 & $+9.25 \%$ & $-100.03 \%$ \\
+6 & $+3.96 \%$ & $-84.00 \%$ \\
\hline \hline
\end{tabular}

Table 3. Overview of the percentage variation in $C_{D} \&$ $\mathrm{C}_{\mathrm{L}}$ values for NACA 0012 rear spoilers

\begin{tabular}{c|c|c}
\hline \hline \multirow{2}{*}{$\begin{array}{c}\text { Angle of } \\
\text { Attack }\left[{ }^{\circ}\right]\end{array}$} & \multicolumn{2}{|c}{ NACA 0012 Rear Spoiler } \\
\cline { 2 - 3 } & \% $\mathrm{C}_{\mathrm{D}}$ Difference & \% $_{\mathrm{L}}$ Difference \\
\hline-6 & $+17.03 \%$ & $-143.13 \%$ \\
-3 & $+14.53 \%$ & $-181.02 \%$ \\
+3 & $+2.06 \%$ & $-146.75 \%$ \\
$\mathbf{+ 6}$ & $\mathbf{- 2 . 1 6 \%}$ & $\mathbf{- 1 1 1 . 2 2 \%}$ \\
\hline \hline
\end{tabular}

\section{CONCLUDING REMARKS}

The aerodynamic activity, drag and lift characteristics of the high-speed race cars were numerically studied in both cases: with and without spoiler. There are two extra advantages to the overall pressure force of the spoiler on the automobile. The first advantage is the raising of pressure force on the rear side of the automotive due to the diffuse impact of the spoiler, and the second gain is the raising of the pressure on the spoiler. Flow isolation is the main consideration for calculating the aerodynamic drag and lift of racing cars. While the aerodynamic lift declined in all eight scenarios after the rear spoilers were added, the aerodynamic drag improved in seven scenarios, except for the NACA 0012 airfoil spoiler with $\mathrm{a}+6^{\circ}$ angle of attack $(2.16 \%$ drag reduction $\& 111.12 \%$ lift reduction). The NACA 0012 airfoil with a $+6^{\circ}$ attack angle is thus deemed to be the most desirable of the rear spoilers analyzed. The maximum lift value was lowered ( $181 \%$ reduced lift) by using the same airfoil with $-3^{\circ}$ angle of attack. The main conclusions of the study as follows:

1. NACA 0012 airfoil has demonstrated greater aerodynamic performance than NACA 2412 airfoil as rear spoiler.

2. Addition of spoiler enhances fuel savings and car stability, as car is balanced more at high speed.

This CFD model based on a more general version of sports car owing to the unavailability of details released on the vehicles studied. In fact, the cooling mechanism within the passenger cabin and engine space has been ignored. These are the sectors where further improvements will be made on subsequent researches.

\section{NOMENCLATURE \\ $\mathrm{C}_{\mathrm{D}} \quad$ Coefficient of drag (dimensionless) \\ $\mathrm{C}_{\mathrm{L}} \quad$ Coefficient of lift (dimensionless) \\ $\rho \quad$ Density, $\mathrm{kgm}^{-3}$ \\ $V \quad$ Inlet velocity, $\mathrm{ms}^{-1}$ \\ A Cross section of car body, $\mathrm{m}^{2}$ \\ $h \quad$ Thermal enthalpy, J \\ $k \quad$ Turbulence kinetic energy, $\mathrm{J} / \mathrm{kg}$}

\section{Greek symbols}

$\begin{array}{ll}\delta_{i j} & \text { Kronecker delta } \\ \mu & \text { Dynamic viscocity, Pa.s. } \\ \mu_{t} & \text { Turbulent eddy viscocity, } \mathrm{m}^{2} / \mathrm{s}\end{array}$




\section{REFERENCES}

[1] S. Kodiyalam, J. Sobieszczanski-Sobieski, Multidisciplinary design optimisation- some formal methods, framework requirements, and application to vehicle design, International Journal of Vehicle Design 25 (2001).

[2] A. Buljac, I. Džijan, I. Korade, S. Krizmanić and H. Kozmar, Automobile aerodynamics influenced by airfoil-shaped rear wing, International Journal of Automotive Technology 17 (2016) 377-385.

[3] Y. Han, C. S. Cai, J. Zhang, S. Chen and X. He., Effects of aerodynamic parameters on the dynamic responses of road vehicles and bridges under cross winds, Journal of Wind Engineering and Industrial Aerodynamics 134 (2014) 78-95.

[4] W. Yang, E. Deng, M. Lei, P. Zhang and R. Yin, Flow structure and aerodynamic behavior evolution during train entering tunnel with entrance in crosswind, Journal of Wind Engineering and Industrial Aerodynamics 175 (2018) 229-243.

[5] H. S. Hamut, R. S. El-Emam, M. Aydin and I. Dincer, Effects of rear spoilers on ground vehicle aerodynamic drag, International Journal of Numerical Methods for Heat \& Fluid Flow 24 (3), (2014) 627-642.

[6] Road Vehicle Aerodynamics Forum Committee, Aerodynamic Testing of Road Vehicles- Open Throat Wind Tunnel Adjustment (An American National Standard No. J20J2071_199406), SAE, USA (1998).

[7] Xu-xiau Hu and T.T. Eric, A Numerical Study On Rear-spoiler of Passenger Vehicle, International Journal of Mechanical and Mechatronics Engineering (2011).

[8] C. Tsai et al., Computational aero-acoustic analysis of a passenger car with a real spoiler. Applied Mathematical Modelling (2009) 3661-3673.

[9] A. Huminic, G. Huminic and A. Soica, Study of aerodynamics for a simplified car model with the underbody shaped as a Venturi nozzle. International Journal of Vehicle Design (2012).

[10] M. Sadeghizadeh, B. Saranjam and R. Kamali, Experimental and Numerical Investigation of Drag Force at High Speed Diver Motion in Different Depths from Free Surface, Journal of Applied Fluid Mechanics 10 (2017) 343-352.

[11] D. Barbut, E.M. Negrus, CFD analysis for road vehicles- case study, Incas Bulletin 3 (2011) 15-22.

[12] M. Rouméas, P. Gilliéron and A. Kourta, Drag Reduction by Flow Separation Control on a Car after Body, International Journal for Numerical Methods in Fluids (2009) 1222-1240.

[13] E. Guilmineau, Computational Study of Flow around a Simplified Car Body, Journal of Wind Engineering and Industrial Aerodynamics (2008) 1207-1217.

[14] M. Islam, M. Mamun, Computational Drag Analysis over a Car Body, International Conference on Marine Technology, Dhaka, Bangladesh (2010).

[15] K. Inchul, G. Xin and C. Hualei, Development of a rear spoiler of a new type for mini-vans. International Journal of Vehicle Design (2008) 114131.
[16] M. Jahanmiri, M. Abbaspour, Experimental Investigation of Drag Reduction on Ahmed Car Model Using a Combination of Active Flow Control Methods, IJE Transactions A: Basics 24 (4) (2011) 403- 410 .

[17] S.M. Rakibul Hassan et al., Numerical Study on Aerodynamic Drag Reduction of Racing Cars, Procedia Engineering 90 (2014) 308-313.

[18] S.R. Ahmed et al., Some Salient Features of the Time-Averaged Ground Vehicle Wake, SAE Technical Paper Series, International Congress \& Exposition, 1984, Detroit, Michigan.

[19] M. Muttakin et al., CFD modelling to study the influence of activation energy and domain size on adsorption dynamics, Proceedings of International Exchange and Innovation Conference on Engineering and Sciences, Kyushu University, Fukoka, Japan (2017) 105-108.

[20] W. Meile et al., Experiments and numerical simulations on the aerodynamics of the Ahmed body, CFD Letters 3(1) (2011). 